\title{
Efficacy of electroacupuncture for myofascial pain in the upper trapezius muscle: a case series
}

\author{
Eficácia da eletroacupuntura para dor miofascial do músculo trapézio: \\ uma série de casos
}

Maria F. M. Aranha', Marcelo C. Alves', Fausto Bérzin', Maria B. D. Gavião²

\begin{abstract}
Background: Electroacupunture (EA) includes the passage of an electrical current through the acupuncture needle and is commonly used for pain relief. Objective: To evaluate the EA treatment effects for myofascial pain in the upper trapezius muscle. Methods: Twenty women aged ranging from 18 to 40 years (mean=24.95; $\mathrm{SD}=5.88$ years), with a body mass index ranging from 19 to $25 \mathrm{~kg} / \mathrm{m}^{2}$ (mean=22.33; $\mathrm{SD}=0.56 \mathrm{~kg} / \mathrm{m}^{2}$ ), with regular menstrual cycles controlled by oral contraceptive, local or referred pain for more than six months and at least one myofascial trigger point in the upper trapezius participated in this study. The participants received a total of nine EA sessions over five weeks. The needles were inserted at the accupoints GB20, GB21, LV3, LI4, and at "ashi" points. A mixed current of $2 \mathrm{~Hz}$ and $100 \mathrm{~Hz}$ was applied alternatively every 5 seconds for 30 minutes. The outcomes were pain intensity measured by the visual analogue scale (VAS), pressure pain threshold (PPT) measured by an algometer, electromyography (EMG) and quality of life measured by the SF-36 questionnaire. Inter-occurrences between sessions were monitored. Paired t-test, Wilcoxon test, and repeated measure analysis of variance (ANOVA) having Tukey-Kramer as post-hoc tests were used. Results: Significant improvement in pain intensity and in PPT occurred after treatment $(p<0.0001)$. EMG of the right trapezius during contraction increased significantly, suggesting muscle function enhancement; the quality of life improved, related to physical components of the SF-36 $(p<0.05)$. Conclusion: The EA showed to be a reliable method for myofascial pain relief. Large randomized blinded controlled trials might be carried out to confirm these results. Article registered in the Registro Brasileiro de Ensaios Clínicos under number RBR-4hb6f6*
\end{abstract}

Keywords: physical therapy; trigger points; electroacupuncture; electromyography; quality of life; pain threshold.

\section{Resumo}

Contextualização: A eletroacupuntura (EA) inclui a passagem de uma corrente elétrica pela agulha de acupuntura e é comumente utilizada para aliviar a dor. Objetivo: Avaliar o efeito da EA no tratamento da dor miofascial do músculo trapézio superior. Métodos: Participaram

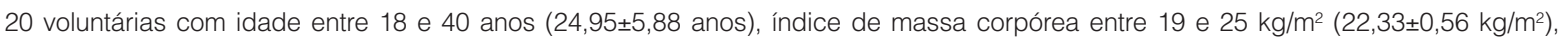
ciclo menstrual regulado por anticoncepcionais, dor por mais de seis meses no trapézio superior, com pelo menos um ponto gatilho miofascial. Nove sessões de EA foram agendadas, sendo duas por semana. As agulhas foram inseridas nos pontos VB20, VB21, F3, IG4 e em pontos ashi. Aplicou-se uma corrente alternada de $2 \mathrm{~Hz}$ e $100 \mathrm{~Hz}$ a cada 5 segundos durante 30 minutos. Avaliou-se a eficácia do tratamento quantificando a intensidade da dor com a Escala Visual Analógica (EVA); o limiar de dor à pressão (LDP), com algômetro digital, eletromiografia (EMG) e com o questionário de qualidade de vida SF-36. Possíveis fatores influenciadores entre as sessões foram monitorados. Aplicaram-se os testes $t$ pareado, Wilcoxon e análise de variância com medidas repetidas (ANOVA) e, como posthoc, o teste de Tukey-Kramer. Resultados: Após o tratamento, houve melhora na intensidade da dor e no LDP ( $p<0,0001)$. A EMG no trapézio direito, durante a contração, aumentou significativamente, sugerindo melhora da função muscular. A qualidade de vida melhorou considerando os componentes físicos do SF-36 ( $p<0,05)$. Conclusão: A EA mostrou-se confiável no alívio da dor miofascial. Estudos randomizados, cegos e controlados devem ser realizados para confirmar esses resultados. Artigo registrado no Registro Brasileiro de Ensaios Clínicos sob o número RBR-4hb6f6*.

Palavras-chave: fisioterapia; pontos desencadeantes miofasciais; eletroacupuntura; eletromiografia; qualidade de vida; limiar da dor.

Received: 09/14/2010 - Revised: 03/02/2011 - Accepted: 06/29/2011

Department of Morphology, Piracicaba Dental School, Universidade Estadual de Campinas (UNICAMP), Piracicaba, SP, Brazil

${ }^{2}$ Department of Pediatric Dentistry, Piracicaba Dental School, UNICAMP

*The trial registration was performed a posteriori.

Correspondence to: Maria Beatriz Duarte Gavião, Faculdade de Odontologia de Piracicaba/UNICAMP, Av. Limeira, 901, CEP 13414-903, Piracicaba, SP, Brasil, e-mail: mbgaviao@fop.unicamp.br 


\section{Introduction $: \because$.}

Muscle pain can be attributed to a myofascial pain disorder $^{1}$. The incidence os muscle pain ranges from 30\% to $93 \%$ depending on the subspecialty practice and setting. Epidemiological studies suggest that myofascial pain syndrome, which includes the presence of myofascial trigger points (MTrPs) is an important musculoskeletal dysfunction ${ }^{2,3}$ and is considered one of main causes of headache and neck pain ${ }^{4}$. It was observed that active MTrPs were more common in subjects with mechanical neck pain than in healthy controls, but individuals without pain can have active or latent MTrPs in the trapezius muscle ${ }^{5}$. Moreover, persistent pain can influence the quality of life in symptomatic patients ${ }^{1}$.

The treatment of myofascial pain disorders requires that symptomatic MTrPs and muscles need to be identified as primary or ancillary pain generators. Acupuncture has been used by physical therapists as an alternative to more traditional treatments for musculoskeletal pain, since it denervates neurophysiologically or physically the neural loop of the trigger point, in order to reduce pain and muscle spasm 5 . Acupuncture stimulates points on the body, manually or electrically, by the insertion of needles to prevent or modify the perception of pain or to alter physiologic functions ${ }^{6}$. The electroacupuncture (EA) includes the passage of an electrical current through the needle ${ }^{7}$ and is supposed to be more effective in relieving pain than manual acupuncture ${ }^{8,9}$. Studies investigating EA mechanisms of action have revealed that endogenous opioid peptides in the central nervous system mediate the analgesic effects produced by this treatment ${ }^{10}$. Thus, the EA is applied at the acupuncture points for stimulating muscle nociceptors, which activate the endogenous antinociceptive system ${ }^{7}$. The World Health Organization endorsed more than 40 disorders that can benefit from acupuncture treatment ${ }^{11}$.

In order to verify the efficacy of interventions in myofascial pain relief, the pressure pain threshold (PPT) and pain intensity can be chosen as possible outcomes. The algometer is an objective method to accurately measure the $\mathrm{PPT}^{12}$. To assess the pain intensity, the visual analogic scale (VAS) has proven to be effective when compared to other instruments ${ }^{13}$. The efficacy of the treatment can be also evaluated by improvements in quality of life, being the SF-36 questionnaire a valid tool ${ }^{14}$.

Another method for testsing muscle disorders is electromyography (EMG), which assess the muscle function by capturing electrical signs deriving from an active muscle ${ }^{15}$ and evaluates different parameters, such as muscle relaxation ${ }^{16,17}$, muscle weakness ${ }^{18,19}$ and activity of motor units ${ }^{20,21}$. Long-term surface EMG recordings have revealed large inter-individual variation in trapezius activation patterns related to individual variation in structural factors (e.g., anatomy, fiber composition), contrasted by intra-individual consistency in repeated recordings likely representing an expression of idiosyncratic muscle activation patterns, i.e., motor habits ${ }^{22,23}$.

This study aimed to analyze the effect of EA in the treatment of MTrPs in patients with chronic pain due to myofascial dysfunction of the upper trapezius muscle, evaluating pain intensity, pressure pain threshold, muscle activity and quality of life.

\section{Methods $: \because$.}

This study was conducted at the electromyography laboratory of the Department of Morphology, Piracicaba Dental School, Universidade Estadual de Campinas (UNICAMP), Piracicaba, SP, Brasil. The Research Ethical Committee of Piracicaba Dental School, UNICAMP, approved the project (protocol 088/2008). The Brazilian Clinical Trials Registry number is UTN: U1111-1122-1815. The volunteers were asked to read and sign the consent form. They were informed about the procedures, discomfort or risks, the benefits as well as the needs to attend all sessions.

Women suffering from neck pain or headache were included. They were carefully examined in order to obtain information about their general health. The inclusion/exclusion criteria were: (1) Inclusion criteria: age ranging from 18 to 40 years, at least one MTrPs in the upper trapezius muscle, local or referred persistent pain for at least six months, regular menstrual cycles controlled by the use of oral contraceptive medication, and be right-handed. (2) Exclusion criteria: postural abnormalities (verified by the physical therapist), presence of fibromyalgia syndrome, cervical radiculopathy, systemic disease or therapeutic interventions for physical myofascial pain within the past month before the study, pregnancy, use of a pacemaker or electronic implants (informed by the subject). The continuous use of medications to treat headache and muscle pain was also considered an exclusion criterion. Moreover, if evident cognitive impairment or communication difficulties were observed by the examiner (MFMA) at the first meeting, the subject was excluded.

Initially, twenty-seven subjects were accessed for eligibility. Three of them were not included, since one was not taking oral contraceptive regularly, and two were older than 40 years, thus 24 were evaluated. From these, four did not present any MTrPs. The final sample was composed of 20 females. Their mean age was $24.95(\mathrm{SD}=5.88)$ years and the body mass index ranged from 19 to $25 \mathrm{~kg} / \mathrm{m}^{2}$ (mean=22.33, $\mathrm{SD}=0.56 \mathrm{~kg} / \mathrm{m}^{2}$ ). All volunteers were diagnosed as having latent MTrPs bilaterally. Each side was analyzed separately. 
The treatment could not be initiating during the premenstrual phase or during menstruation and was conducted over four and a half weeks. The last treatment session coincided with the same menstrual phase than the first treatment session. Additionally, the use of oral contraceptive enabled the confidence about the cycle phase during sessions.

\section{Instrumentation}

The equipment used for the EA was the EL608NKL (ANVISA-80191680002). The stainless steel needles were individually wrapped, sterilized, and disposable with $0.25 \mathrm{~mm}$ in diameter and $30 \mathrm{~mm}$ in length (Dong-Bang, Korea).

The Visual Analogue Scale (VAS) was used to assess the intensity of pain. The scale consists of an horizontal line of 10 centimeters in length, with zero meaning "no pain" and 10 meaning "maximum pain". The PPT was measured using a DDK/20 digital algometer (Kratos Industrial Equipment), containing a bar with a flat circular tip with $1 \mathrm{~cm}$ diameter.

The electromyographic signals were recorded using ADS1200 Lynx equipment with 8 channels, a gain variable of 1-16000, a sampling frequency of $2000 \mathrm{~Hz}$ for each channel, a band-pass filter of 20-500 Hz and a PCI A/D conversion with 14-bit resolution, where signals were scanned and stored in a computer. The electrodes were disposable passive bipolar of $\mathrm{Ag} / \mathrm{AgCl}$, in double circular format with $1 \mathrm{~cm}$ inter-electrode distance (Hal Indústria e Comércio Ltda, São Paulo, SP, Brazil) and a gain of 20 times. The reference electrode was positioned in the notch of the sternum in order to remove noise from the acquisition. Signal visualization and processing were performed with AqDAnalysis software. The EMG values were expressed by root mean square (RMS).

Quality of life was assessed by the Portuguese version of the SF-36, consisting of 36 questions that evaluates eight domains: physical functioning, role-physical, bodily pain, role-emotional, general health, vitality, social functioning and mental health. The psychometric properties of the SF-36 were previously tested ${ }^{14}$.

The additional data form (ADF) consisted of opened questions to be answered at the beginning of the sessions for monitoring inter-occurrences between sessions, such as traumas, headache, neck and shoulder pain, eventual medication and dose used. These inter-occurrences were asked because the latent MTrPs could turn active and referred pain could be arising spontaneously. Additionally, distressful conditions that could be occurred between sessions should be informed, since muscle tension can be expressed by anxiety and emotional ten$\operatorname{sion}^{1}$. Those conditions were considered as influencing factors, i.e., they could confound treatment effects. The pain intensity in every session was measured by the VAS.

\section{Procedures}

The diagnosis of MTrP was based on five criteria $^{1,23}$ : (1) presence of a palpable taut band in the muscle; (2) presence of a hypersensitive tender spot in a taut band; (3) local twitch response elicited by the snapping palpation of the taut band; (4) reproduction of the typical referred pain pattern of the MTrP in response to compression; (5) spontaneous presence of the typical referred pain pattern and/or recognition of the referred pain as familiar. If the first four criteria were satisfied, the MTrP was considered to be latent. If all of the criteria were present, the MTrP was considered to be active $e^{1,23}$. The participant was examined in prone position $^{1}$.

All nine sessions were scheduled at the same time of the day. Each volunteer received two sessions per week. The scheduled sessions and procedures are shown in Figure 1. The SF-36 was applied at the beginning of the first and the ninth sessions, the $\mathrm{ADF}$ in the beginning of every session, following by the VAS; EMG and PPT were assessed during the first, third and ninth sessions.

During EA application, the patient remained sited in a chair. Needles were inserted bilaterally in the points GB21, GB20, LI4, $\mathrm{LV}^{24}$ and directly in the region of the MTrPs (using a maximum of four needles). The equipment was programmed as follows: alternating frequency $\mathrm{F} 1=2 \mathrm{~Hz}, \mathrm{~T} 1=5$ seconds, $\mathrm{F} 2=100 \mathrm{~Hz}, \mathrm{~T} 2=5$ seconds; total time: 30 minutes; intensity: maximum supported by the patient without pain. These parameters were used in all sessions.

To assess PPT, the algometry was first demonstrated on the forearm, so the volunteers could familiarize with the equipment ${ }^{25}$ and feel the pressure, which would be exerted on the trapezius muscles. After, the digital algometer was applied on upper trapezius, half way between the seventh cervical vertebra and the tip of the acromion bilaterally, increasing the pressure at a rate of $0.5 \mathrm{kgf} / \mathrm{s}$ until the volunteer reported a painful sensation. The procedure was repeated three times, and the mean value was considered.

EMG electrodes were placed at the upper trapezius muscle half way between the seventh cervical vertebra (C7) and acromion $^{26}$. The exam was conducted with the participant seated on a chair. The participant was asked to maintain the trapezius muscle at a resting position for six seconds followed by raising both shoulders, keeping this position in isometric contraction for six seconds, prompted by an adequate verbal command. The volunteers had been previously trained to perform the required tasks. Each task was performed three times (with one minute interval) and the mean RMS was used. 


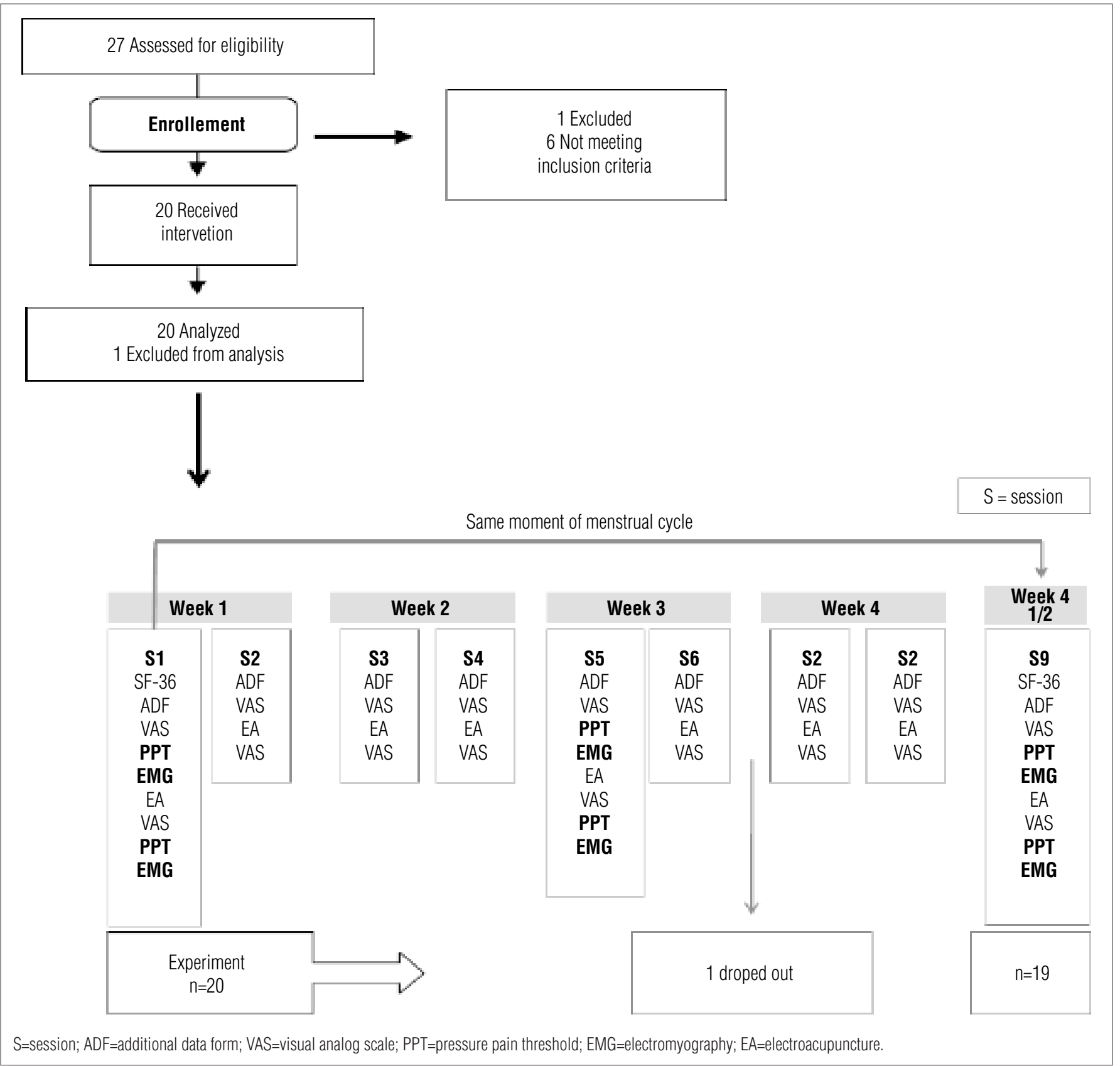

Figure 1. Enrollment of participants and study design.

\section{Statistics}

The assumptions of equality of variances and normal distribution of errors were checked for all variables using the Shapiro-Wilk test. Symmetry was quantified by skewness statistic and the values greater than 2 in absolute terms were treated as assymmetric. The student's paired t-test was used when the normality was verified. The Wilcoxon signed rank test was applied to assymmetric data and the sign test to assymmetric data. Repeated measure analysis of variance with Mixed Models compared the fixed effect of the session, having Tukey-Kramer as post-hoc. Effect of volunteer was treated as random. A model was estimated by Restricted Maximum Likelihood and with an autoregressive matrix of covariance. For this analysis, the data before the EA application in each session and after the EA application were considered. The level of significance was set at $5 \%$. It was used the SAS System (Release 9.1.3-SP 4. SAS Institute Inc., Cary, NC, USA, 2002).

\section{Results $: \because$}

The number of MTrPs found in the right upper trapezius during the first evaluation was $2.05(\mathrm{SD}=0.15)$ and on the left 
upper trapezius, 2.45 (SD=0.24). The mean value of pain duration was $5.55(\mathrm{SD}=0.86)$ years.

\section{Intensity of pain}

A reduction in pain intensity was observed on the upper trapezius muscle on both sides after all nine sessions ( $<<0.0001)$. From sessions 1 to 5 and sessions 8 and 9 the pain intensity was significantly lower after the EA on both sides $(\mathrm{p}<0.05)$. In session 6 , only the left trapezius showed significant improvement after $\mathrm{EA}(\mathrm{p}=0.012)$. In session 7 , there was not a significant difference after EA (Figure 2).
The comparisons among sessions showed significant improvement in pain intensity in session 7 in relation to the first three sessions, before and after EA application, with the exception of the right trapezius in which the improvement was significant in session 8 . These improvements were maintained until the end of the treatment.

\section{Pain pressure threshold}

The PPT increased significantly on both sides at the end of the treatment $(\mathrm{p}<0.0001)$, and after EA in the first, fifth and ninth sessions $(\mathrm{p}<0.0001)$ (Figure 3$)$.

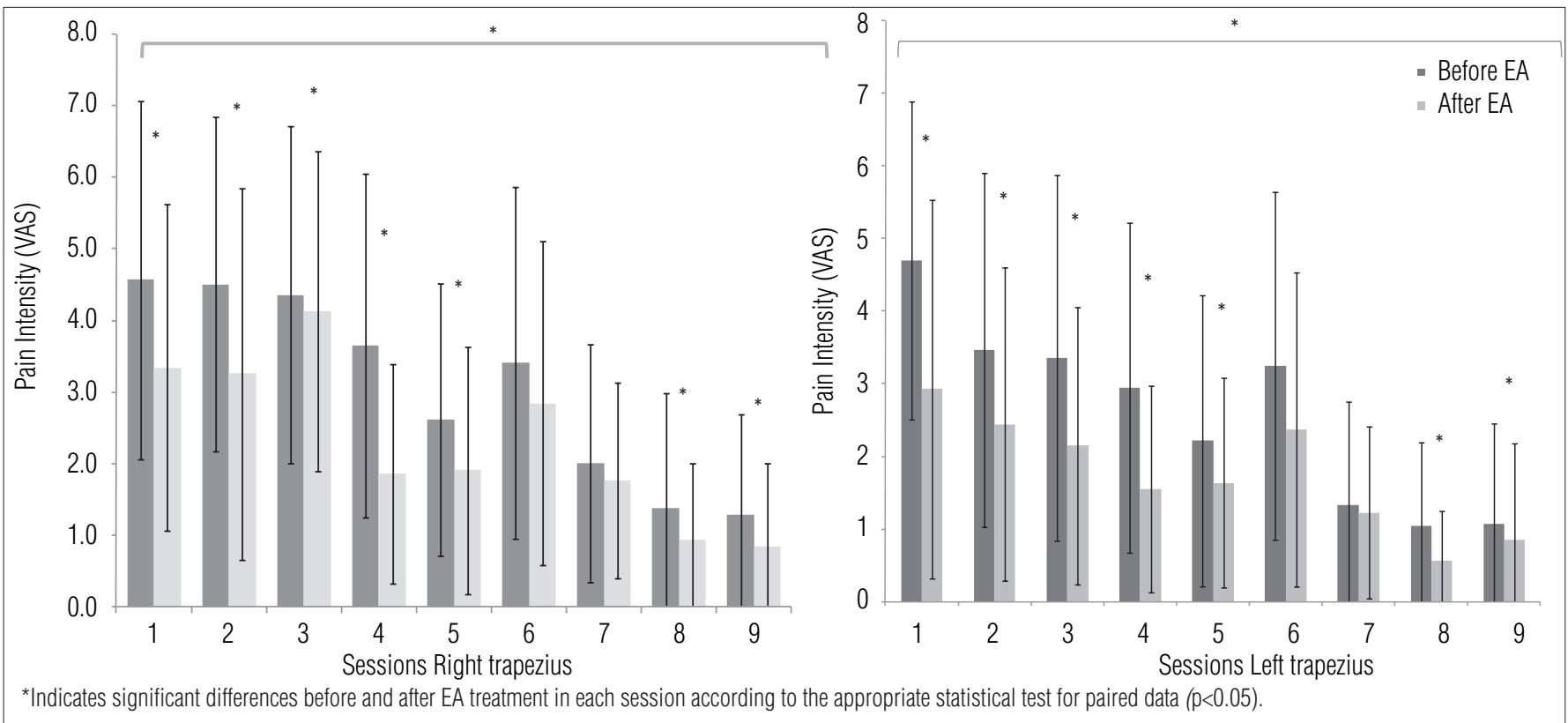

Figure 2. Means and standard deviations of pain intensity (VAS) in the right and left trapezius muscle.

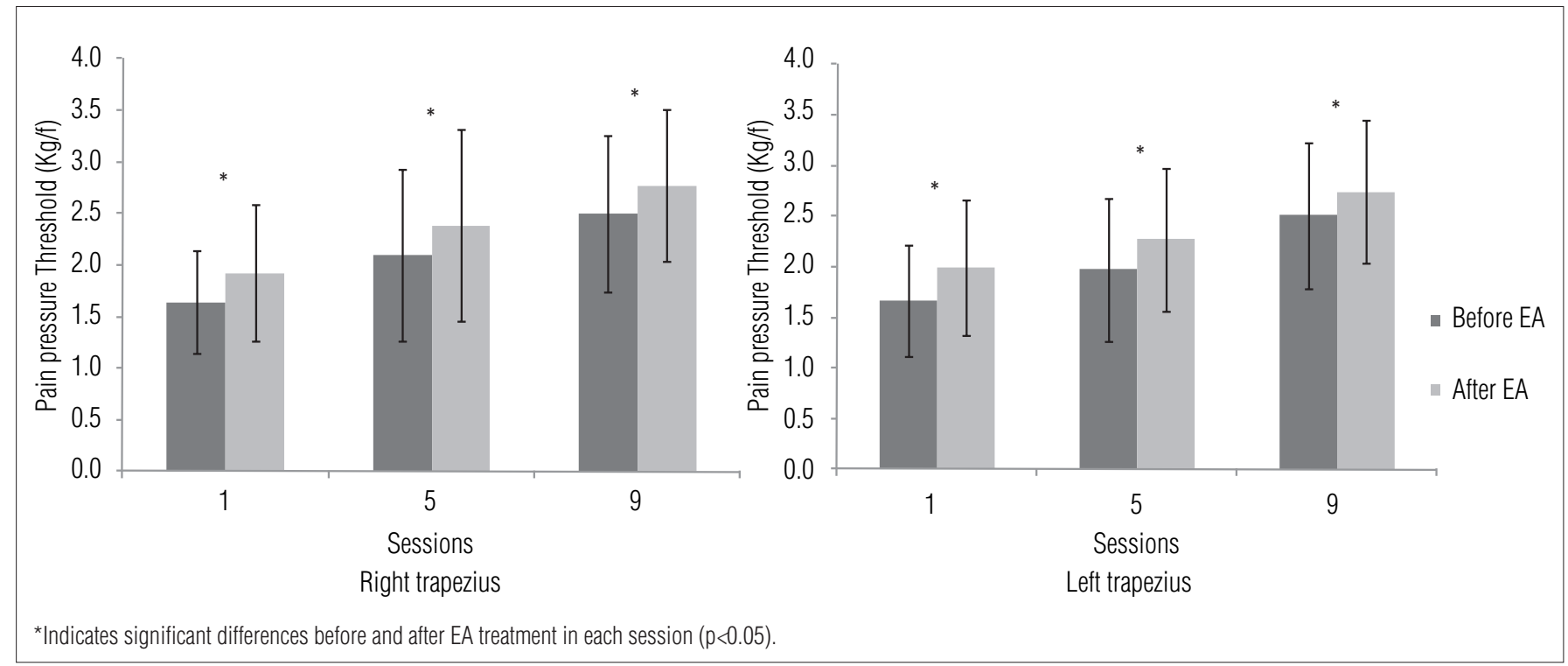

Figure 3. Means and standard deviations for PPT in the upper right (A) and left (B) trapezius muscle according to statistical analyses for paired data. 


\section{EMG}

A significant increase in the EMG values of the right trapezius during isometric contraction was observed at the end of treatment ( $\mathrm{p}=0.03$ ). The left trapezius almost showed a significant increase, but the test failed to detect a significant difference at a 5\% level $(\mathrm{p}=0.0506)$. However, the left trapezius showed a significant increase in the respective RMS values during isometric contraction before and after the EA in the ninth session $(\mathrm{p}=0.0468)$.

\section{Quality of life (SF-36)}

Statistically significant improvements were observed in the following domains: role-physical $(\mathrm{p}<0.05)$ and bodily pain $(\mathrm{p}<0.05)$ (Figure 4).

\section{Additional Data Form (ADF)}

Overall, there was an improvement concerning the data from the ADF (Figure 5). The reductions in the use of

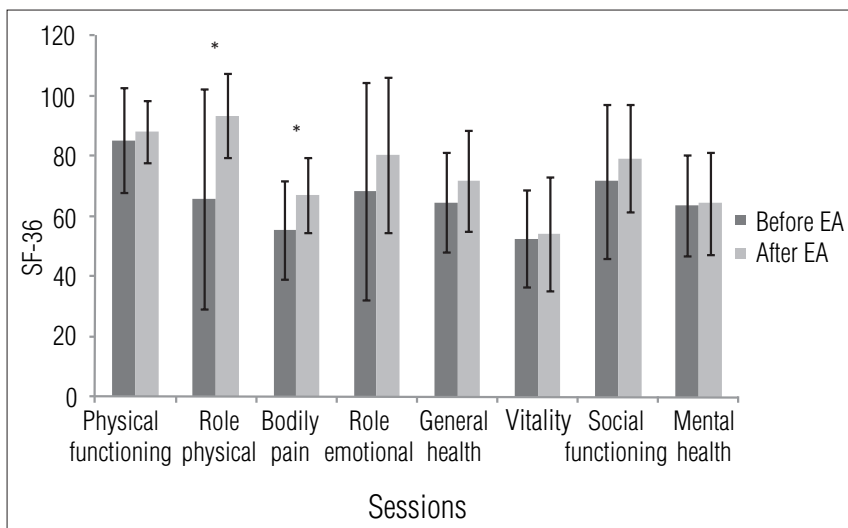

*Indicates significant differences before and after EA treatment according to statistical analyses for paired data $(p<0.05)$.

Figure 4. Means and standard deviations for the eight domains of the SF-36 questionnaire.

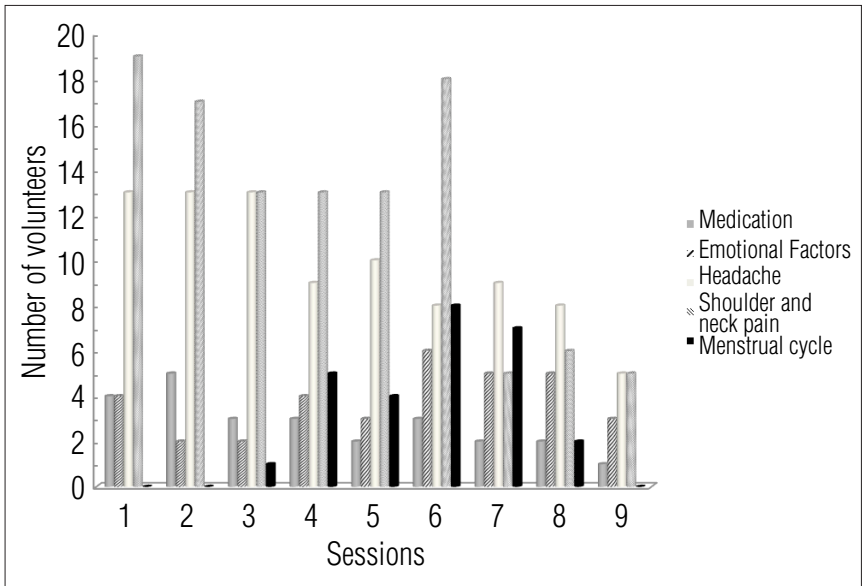

Figure 5. Sample distribution in relation to influencing factors occurred between two consecutive sessions. medications and the incidence of headache and pain in the trapezius between sessions are indicative of this improvement. At the sixth session, there was an increase in emotional factors and also in the number of volunteers who were in the menstrual phase.

\section{Discussion $\because \because$.}

\section{Pain intensity, PPT and ADF}

The improvements in pain corroborate with previous studies, in which subjects were assessed after one ${ }^{27,28}$ or several sessions of $\mathrm{EA}^{29-31}$. At the right trapezius, after the third session, the analgesic effect was maintained until the next session, suggesting a cumulative effect of EA. In the left trapezius, this effect was observed in the beginning of treatment. Despite that, the carryover effects of the EA should be determined with a control group that was not used in this study and should be considered as a limitation. However, there was a recurrence of pain in both sides at the sixth session (Figures 2 and 3). It can be speculated that this worsening of pain may be related to the menstrual cycle, since at the sixth session, $30 \%$ of volunteers were in the follicular phase, when pain threshold may be decresead ${ }^{25}$.

The timing of the menstrual cycle was considered for starting the treatment. In accordance with members of the Sex, Gender and Pain Special Interest Group of the International Association for the Study of Pain ${ }^{32}$ if menstrual cycle itself is not a factor to be evaluated, the research should plan to evaluate females in the same phase of their cycle, since both absolute and relative hormonal levels could influence pain. Start date of the last menstrual period can be reliably obtained from self-report. Additionally, all volunteers were using contraception medication guarantying that women with irregular cycles were included ${ }^{32}$. Moreover, in the sixth session, an increase in the use of medications occurred, as well as an increase in the emotional factors, such as family problems, problems in employment or academic examinations, and neck and shoulder pain, which may have influenced the recurrence of pain at that time. Nevertheless, we did not intend to quantify the influencing factors upon the treatment results, inferring that further researches may take into account those variables.

The parameters for the EA equipment were adjusted in the same way for all volunteers, who received the same stimulus. A change in stimulus, considering individual needs is likely to provide analgesic effects in a shorter period of time; as this preliminary study has not blinded the examiner, the same stimulus for all volunteers might minimize possible bias. The advantage of a dense-and-disperse mode of stimulation designed, where $2 \mathrm{~Hz}$ was automatically alternating with $100 \mathrm{~Hz}$, evoking the release 
of both opioid peptides, the enkephalins and dynorphins, resulting in a synergistic interaction, was previously found ${ }^{33,34}$, corroborated in women undergoing major gynecological procedures ${ }^{35}$, and in normal volunteers, who received electric stimulation over the anterior aspect of the dominant forearm ${ }^{36}$.

There was an increase in the PPT after all evaluated sessions $(1,5,9)$ and also at the end of treatment, indicating lower pain sensitivity, demonstrating the effectiveness of EA. Other studies that involved the treatment with EA found similar results after one treatment session ${ }^{28}$ and after 10 sessions $^{29}$. There was no recurrence of pain, as observed in the pain intensity by VAS, which may have occurred as a result of the sessions in which the data were evaluated. Besides the influence of the follicular phase of menstrual cycle upon pain intensity, as cited above, the controversial results, considering VAS and PPT, could be explained by the fact that the VAS score has a subjective and emotional components ${ }^{37}$, whereas in pressure algometry the reference is more quantitative and associated with nociceptive sensibility based on a mechanical stimulus ${ }^{28}$. Moreover, the points chosen for algometry were close to the points of insertion needles, generating electrical stimulus and enhancing local effect during assessment, as previously observed ${ }^{23}$. Furthermore, no analgesic effects were observed leaving the needle in situ without movement or electrical stimulation ${ }^{35}$. Thus, it may be interesting to try EA rather than using only manual needling in randomized controlled trials ${ }^{11}$.

\section{EMG}

At rest, there was no significant difference between RMS values in each session or in the whole treatment, likely by the presence of latent MTrPs. Chou et al. ${ }^{38}$ observed a significant reduction in the upper trapezius EMG signal at rest after dry needling of the MTrP. The differences between studies are probably due to the type of MTrP but may also be due to the technique applied. They treated active MTrPs with RMS values at rest close to $7 \mu \mathrm{v}$ and obtained values close to $3 \mu \mathrm{v}$ after the dry needling, which is very similar to those obtained in the current study before treatment. Indeed, the data provided by EMG at rest were not reliable for detecting respective muscle alterations, despite the fact that the pain had been clinically observed.

Beyond pain, muscles with MTrPs generally present associated symptoms as muscular weakness. Although a measurement of strength was not considered, the increase in the EMG during the sustained contraction of right trapezius could indicate an improvement of muscle function and an effective action of EA upon myofascial pain. Although the left trapezius did not demonstrate similar results, the lack of significance should be carefully interpreted. Moreover, all volunteers were right-handed, so the right side was less prone to muscle fatigue (EMG) than the left ${ }^{39}$. The extended preferential use of a muscle can induce changes in the muscle fiber membrane and its regulatory properties, justifying the difference in behavior ${ }^{39}$. Perhaps these changes interfered with muscle recovery. It was already demonstrated that EMG of the upper trapezius during contraction in subjects with pain showed lower RMS values when compared to the normal controls ${ }^{40,41}$.

\section{Quality of life}

There was improvement in the quality of life after treatment with EA, especially in the domains "Role-Physical" and "Bodily Pain". Díaz Arribas et al. ${ }^{42}$ using SF-36 to assess volunteers with low back pain also noted an improvement in quality of life after 15 sessions and improvement in pain, in the domains "physical components" and "mental elements". The two areas with significant improvement in the present study belong to the "physical components". It is possible that the absence of the influence of pain symptoms in the other SF-36 domains occurred due to the shorter treatment period and the lower number of sessions. No improvement in the quality of life (SF-36) after six sessions of EA was found, due to any significant improvement in chronic pain ${ }^{43}$. Moreover, the volunteers' MTrPs in the present study were latent, and consequently did not incapacitate them and did not influence all SF domains, despite the clinical improvement.

\section{Study limitations}

For further studies, the monitoring of the force during isometric contraction using a load cell could improve the EMG data collection, since it offers a way for reliable evaluations concerning their maximum effort, allowing more consistent data analysis.

Although the small sample was a potential limitation, the improvement obtained with EA was sufficient to consider its efficacy on pain in the trapezius muscle, adding one more option for physical therapists. Considering the expected preliminary results, each volunteer was their own control, since pain subjectivity could cause misinterpretation on comparing different individuals. Nevertheless, further randomized blinded controlled trials must be conduct with larger sample including other treatments, as well as different types of pain, in order to validate our findings. In this context, we determined the sample size, basing in the statistical power of 0.90. A two-sided test with $\alpha=0.05$ was applied in accordance with the experimental conditions : for pain intensity, considering the null mean $=0$, the alternate mean $=1.5$, and the standard deviation $=2.5$, the sample size must be composed by 32 subjects. For pain pressure 
threshold, the respective values were 0.50 and 0.80 indicating 29 subjects, whereas for electrical activity 40 and 70, indicating 35 subjects. Our results with 20 volunteers showed a power of 0.70 for pain intensity, 0.75 for pain pressure threshold and 0.67 for EMG. The determined sample sizes for a power of 0.90 will guarantee more reliable answers for clinical questions.

In summary, EA was effective to relief myofascial pain in the studied sample, since decrease pain intensity and pain pressure threshold decreased. There was an increase in EMG during contraction of right trapezius at the end of treatment and in the left one during last session, suggesting muscle function enhancement provided by EA. Furthermore, the quality of life was improved, related to physical components domain of the SF-36. In accordance with these preliminary findings, the electroacupuncture can be considered a relevant tool for the management of myofascial pain in the health area, specifically in the Physical therapy.

\section{Acknowledgments $: \because$.}

The Fundação de Amparo a Pesquisa do Estado de São Paulo (FAPESP). Financial support from the Coordenação de Aperfeiçoamento de Pessoal de Nivel Superior (CAPES) for the acquisition of EMG equipment is greatly appreciated. The authors thank the volunteers for their participation.

\section{References $\because \ldots$}

1. Simons DG, Travell JG, Simons LS. Myofascial pain and dysfunction: The trigger Point Manual. Baltimore: Williams \& Wilkins; 1999.

2. Gerwin RD. Differential diagnosis of myofascial pain syndrome and fibromyalgia. J Musculoskel Pain. 1999;7(1):209-15.

3. Skootsky SA, Jaeger B, Oye RK. Prevalence of myofascial pain in general internal medicine practice. West J Med. 1989;151(2):157-60.

4. Grosshandler SL, Stratas NE, Toomey TC, Gray WF. Chronic neck and shoulder pain. Focusing on myofascial origins. Postgrad Med. 1985;77(3):149-51, 154-8.

5. Fernández-de-Las-Peñas C, Alonso-Blanco C, Miangolarra JC. Myofascial trigger points in subjects presenting with mechanical neck pain: A blinded, controlled study. Man Ther. 2007;12(1):29-33

6. Stux G, Pomeranz B. Basics of acupuncture. Berlin: Springer-Verlag; 1995

7. Koski BL, Dunn KS, Shebuski MR. Daily activity patterns of an adult experiencing lower back pain undergoing electro-acupuncture: a case study. Pain Manag Nurs. 2009;10(4):188-196.

8. Wan Y, Wilson SG, Han J, Mogil JS. The effect of genotype on sensitivity to electroacupuncture analgesia. Pain. 2001;91(1-2):5-13

9. Kim HW, Roh DH, Yoon SY, Kang SY, Kwon YB, Han HJ, et al. The anti-inflammatory effects of low- and high-frequency electroacupuncture are mediated by peripheral opioids in a mouse air pouch inflammation model. J Altern Complement Med. 2006;12(1):39-44.

10. Walling A. Therapeutic modulation of the psychoneuroimmune system by medical acupuncture creates enhanced feelings of well-being. J Am Acad Nurse Pract. 2006;18(4):135-43.

11. Han JS. Acupuncture analgesia: areas of consensus and controversy. Pain. 2011;152(3 Suppl):S41-8.

12. Visscher CM, Lobbezoo F, Naeije M. Comparison of algometry and palpation in the recognition of temporomandibular disorder pain complaints. J Orofac Pain. 2004;18(3):214-9.

13. Jensen MP, Turner JA, Romano JM, Fisher LD. Comparative reliability and validity of chronic pain intensity measures. Pain. 1999;83(2):157-62.

14. Ciconelli RM, Ferraz MB, Santos W, Meinão I, Quaresma MR. Brazilian-Portuguese version of the SF-36. A reliable and valid quality of life outcome measure. Rev Bras Reumatol. 1999;39(3): $143-50$

15. Basmajian JV, De Luca CJ. Muscle Alive: their function revealed by electromyography. Baltimore: Willams and Wilkins; 1985

16. Labyt E, Cassim F, Szurhaj W, Bourriez JL, Derambure P. Oscillatory cortical activity related to voluntary muscle relaxion: influence of normal aging. Clin Neurophysiol. 2006;117(9): 1922-30.

17. Voerman GE, Sandsjö L, Vollenbroek-Hutten MM, Groothuis-Oudshoorn CG, Hermens HJ. The influence of different intermittent myofeedback training schedules on learning relaxation of the trapezius muscle while performing a gross-motor task. Eur J Appl Physiol. 2004;93(1-2):57-64.
18. Hjortskov N, Essendrop M, Skotte J, Fallentin N. The effect of delayed-onset muscle soreness on the stretch reflexes in human low back muscles. Scan J Med Sci Sports. 2005;15(6):409-15.

19. Nie H, Arendt-Nielsen L, Kawczynski A, Madeleine P. Gender effects on trapezius surface EMG during delayed onset soreness due to eccentric shoulder exercise. J Electromyogr Kinesiol. 2007;17(4):401-9.

20. Lochyński D, Celichowski J, Korman P, Raglewska P. Changes of motor unit contractile output during repeated activity. Acta Neurobiol Exp (Wars). 2007;67(1):23-33

21. Saboisky JP, Butler JE, Walsh LD, Gandevia SC. New display of the timing and firing frequency of single motor units. J Neurosci Methods. 2007;162(1-2):287-92.

22. Ge HY, Wang Y, Fernández-de-Las-Peñas C, Graven-Nielsen T, Danneskiold-Samsøe B, ArendtNielsen L. Reproduction of overall spontaneous pain pattern by manual stimulation of active myofascial trigger points in fibromyalgia patients. Arthritis Res Ther. 2011;13(2):R48

23. Gerwin RD, Shannon S, Hong CZ, Hubbard D, Gevirtz R. Interrater reliability in myofascial trigger point examination. Pain. 1997;69(1-2):65-73.

24. Lin YL, Chen CY, Hammes M, Kolster BC. Atlas gráfico de acupuntura. São Paulo: Konemann port; 2005.

25. Isselée H, De Laat A, De MotB, Lysens R. Pressure-pain threshold variation in temporomandibular disorder myalgia over the course of the menstrual cycle. J Orofac Pain. 2002;16(2):105-17.

26. Surface ElectroMyoGraphy for the Non-Invasive Assessment of Muscles. Accessed January 21 2009. Available at: www.senian.org

27. Lundeberg T. Comparative study of the pain alleviating effect of vibratory stimulation, transcutaneous electrical nerve stimulation, electroacupuncture and placebo. Am J Chin Med 1984;12(1-4):72-9.

28. Nohama P, Silvério-Lopes SM. Influence of the stimulating frequency involved in analgesic effects induced by electroacupuncture for neck pain due to muscular tension. Rev Bras Fisioter. 2009:13(2):152-8

29. He D, Veiersted KB, Høstmark AT, Medbø Jl. Effect of acupuncture treatment on chronic neck and shoulder pain in sedentary female workers: a 6-month and 3-year follow-up study. Pain. 2004;109(3):299-307

30. List T, Helkimo M, Andersson S, Carlsson GE. Acupuncture and occlusal splint therapy in the treatment of craniomandibular disorders. Part I. A comparative study. Swed Dent J. 1992;16(4):125-41.

31. Xue CC, Dong L, Polus B, English RA, Zheng Z, Da Costa C, et al. Electroacupuncture for tensiontype headache on distal acupoints only: a randomized, controlled, crossover trial. Headache. 2004;44(4):333-41.

32. Greenspan JD, Craft RM, LeResche L, Arendt-Nielsen L, Berkley KJ, Fillingim RB, et al. Studying sex and gender differences in pain and analgesia: a consensus report. Pain. 2007;132 Suppl 1:S26-45.

33. Chen XH, Guo SF, Chang CG, Han JS. Optimal conditions for eliciting maximal electroacupuncture analgesia with dense-and-disperse mode stimulation. Am J Acupunct. 1994;22(1):47-53. 
34. Han JS. Acupuncture and endorphins. Neurosci Lett. 2004;361(1-3):258-61.

35. Hamza MA, White PF, Ahmed HE, Ghoname EA. Effect of the frequency of transcutaneous electrical nerve stimulation on the postoperative opioid analgesic requirement and recovery profile. Anesthesiology. 1999;91(5):1232-8.

36. Tong KC, Lo SK, Cheing GL. Alternating frequencies of transcutaneous electric nerve stimulation: does it produce greater analgesic effects on mechanical and thermal pain thresholds? Arch Phys Med Rehabil. 2007;88(10):1344-9.

37. Ferreira PEMS. Dor crônica, avaliação e tratamento oncológico. In: Andrade Filho ACC. Dor, diagnóstico e tratamento. São Paulo: Roca; 2001. p. 43-52.

38. Chou LW, Hsieh Y, Kao M, Hong CZ. Remote influences of acupuncture on the pain intensity and the amplitude changes of endplate noise in the myofascial trigger point of the upper trapezius muscle. Arch Phys Med Rehabil. 2009;90(6):905-12.

39. Farina D, Kallenberg LAC, Merletti R, Hermens HJ. Effect of side dominance on myoelectric manifestations of muscle fatigue in the human upper trapezius muscle. Eur $\mathrm{J}$ Appl Physiol 2003;90(5-6):480-8.

40. Kallenberg LA, Schulte E, Disselhorst-Klug C, Hermens HJ. Myoelectric manifestations of fatigue at low contraction levels in subjects with and without chronic pain. J Electromyogr Kinesiol. 2007;17(3):264-74

41. Schulte E, Kallenberg LA, Christensen H, Disselhorst-Klug C, Hermens HJ, Rau G, et al Comparison of the electromyographic activity in the upper trapezius and biceps brachii muscle in subjects with muscular disorders: a pilot study. Eur J Appl Physiol. 2006;96(2):185-93.

42. Díaz Arribas MJ, Ramos Sánchez M, Pardo Hervás P, López Chicharro J, Angulo Carreré T, Ortega Molina P, et al. Effectiveness of the physical therapy Godelive Denys-Struyf method for nonspecific low back pain: primary care randomized control trial. Spine (Phila Pa 1976). 2009;34(15):1529-38.

43. Zheng Z, Guo RJ, Helme RD, Muir A, Da Costa D, Xue CC. The effect of electroacupuncture on opioid-like medication consumption by chronic pain patients: a pilot randomized controlled clinical trial. Eur J Pain. 2008;12(5):671-6. 